\title{
Fraud and other matters?
}

SIR-While reading the article (Nature 325, 207; 1987) by Stewart and Feder, I found myself increasingly disturbed by issues peripheral to that of direct fraud.

Stewart and Feder seem to have forgotten that the 18 "full-length" research papers were supposedly peer-reviewed. Ought not the reviewers to have questioned the "errors" and "lapses" identified by Stewart and Feder (for example, the ages of parents and siblings in ref. 87)? The peer-review system is designed to prevent such things from occurring. It appears to be failing miserably, which I find more disturbing than any of the allegations made by Stewart and Feder. Perhaps the scientific community would do better if it turned its attention away from sensationalized individual instances and addressed this commonplace but probably more damaging malady.

Equally alarming is the assertion by Braunwald in his response (Nature, 325, $215 ; 1987)$ that the republication of abstract 70 as abs. 78 is legitimate on the grounds that abs. 70 had been rejected. I have personally undertaken a survey of medical and dental school deans, all of whom unanimously agreed that, to their knowledge, rejected abstracts are not published by Clinical Research, Circulation or any other journal. Braunwald put himself in the position of answering an allegation of dishonesty with another. How was abs. 70 both published and rejected by the American Federation for Clinical Research? As one dean asked, is the inclusion of rejected abstracts, manuscripts and funding proposals in one's vitae a standard practice at Harvard? If such an institution condones such practices, how can one of its junior faculty members (Darsee) be criticized for bending other conventions?

Northwestern University,

Michael J. Glade

Medical School,

Department of Pharmacology,

303 E. Chicago Ave,

Chicago, Illinois 60611, USA

BRAUNWALD REPLIES - Abstract no. 70, which Michael Glade refers to, was submitted for presentation to the American Federation for Clinical Research. Clinical Research, the journal of this society, has the unusual policy of publishing all submitted abstracts, regardless of whether or not they are accepted for oral presentation. Indeed, only a fraction of submitted abstracts are accepted for oral presentation. This particular abstract was not accepted for oral presentation. The abstract was slightly revised and then submitted for consideration for presentation before the Scientific Sessions of the American Heart Association and was accepted for oral presentation and pub- lished in Circulation (Abstract no. 78). This sequence is not considered inappropriate by either society.

I am not aware that I or anyone at Harvard has included rejected manuscripts in either vitae or funding proposals and am not sure what Glade was referring to.

Brigham and Women's Hospital,

75 Francis Street, Boston,

Massachusetts 02115, USA

\section{Primary misnomer}

SIR-I should like to call attention to the inappropriate usage of 'primary sequence' as a term to describe the first level of protein structure. By all conventions this phraseology is a misnomer; certainly, 'logical' extensions such as 'secondary sequence' and 'tertiary sequence' are fictitious. Rather, this element of protein structure should be referred to as 'aminoacid sequence', 'primary structure' or 'covalent structure' (see, for example, $J$. biol. Chem. 251, 11-12; 1976).

My concern stems from the alarming increase in frequency with which this misnomer is being used at major scientific meetings and in many internationally recognized publications. For example, a computer-assisted search of the literature for the past three years shows that 'primary sequence(s)' has appeared in journal titles at least 18 times and in abstracts at least 140 times; the journals 'represented' frequently include Nature, Science, Proceedings of the National Academy of Sciences of the USA, Journal of Biological Chemistry, Nucleic Acids Research, EMBO Journal, Journal of Virology, Biochemistry, Journal of Molecular Biology and FEBS Letters.

Shaun D. Black Pharmacognosy,

College of Pharmacy,

Ohio State University,

Columbus, Ohio 43210, USA

\section{Dating the Shroud}

SIR-My first reaction to the letter from Denis Dutton (Nature 327, 10; 1987) was one of satisfaction that concern should be expressed about the protocols for the tests to carbon-date the Shroud of Turin.

However, on reflection I realized that his remarks were a gross insult to the 22 experts who met in Turin between 29 September and 1 October 1986 to work out the procedure to be used in carbondating the Shroud. The remarks also cast a shadow on the integrity of the guarantor from the British Museum and the seven laboratories taking part in the tests
(Nature 323, 486; 1986). It implies, too, that the 40 scientists involved in the STURP investigations of 1987 would stand by and allow their credibility to be sacrificed by some sleight-of-hand trick with the samples.

Then I recalled that the US Committee for the Scientific Investigation of Claims of the Paranormal has a long history of hostility to the claims made for the Shroud of Turin. Unfortunately, the committee can hardly be regarded as having a reasonable and open-minded approach to the subject.

The problem facing Dutton and the US committee is that they fail to realize that proving the shroud to be a mediaeval forgery no more disproves the existence and claims of Jesus Christ than does the discovery, for instance, that a particular lock of hair could not have come from Napoleon would disprove that he existed.

However, if the Shroud is shown to be a mediaeval forgery, science will still be left with the question of how a mediaeval artist produced a three-dimensional photographic image of a body in an advanced state of rigor mortis complete with anatomical details that can be recognized by physicians and forensic pathologists.

Thus whatever the results of the carbondating of the shroud, there will be much work for dedicated scientists, as distinct from stage magicians, to carry out to resolve the mystery of the shroud. Whatever the result, I feel that the "deep religious passions" will be displayed by the Denis Dutton school of thought and not by the scientific community, whose aim is to establish the truth.

CSIRO Division of Mineral Chemistry,

PO Box 124,

Port Melbourne,

Victoria 3207, Australia

\section{How no green cow}

SiR-Ralph A. Lewin's question "Why are cows not green?" (Nature 326, 743-74; 1987) can be generalized: why are there no green mammals? Green would be the optimal colour for camouflage in grassland and forest environments, and there are plenty of green birds, reptiles and amphibians, not to mention invertebrates. For that matter, few mammals have bright colours of any kind. Can we have inherited from drab nocturnal ancestors deficiencies in our system of pigmentation so deep-seated that tens of millions of years of evolution have failed to correct them? Perhaps coloured clothing was the first conspicuous triumph of cultural developments.

University of $O x$ ford,

Philip J. STEWART

The Pauling Human Sciences Centre,

58 Banbury Road,

Oxford OX2 6QS, UK 